\title{
Epidemiological profile and clinical characteristics of inflammatory bowel diseases in a Brazilian referral center
}

\author{
Luiza Maria Pilau FUCILINI, Lívia Moreira GENARO, Daniela Cunha e SOUSA, \\ Cláudio Saddy Rodrigues COY, Raquel Franco LEAL and Maria de Lourdes Setsuko AYRIZONO
}

ABSTRACT - Background - The increase in the incidence and prevalence rates of inflammatory bowel disease (IBD) is evident in many newly industrialized countries in Asia, Africa, Eastern Europe, and the American continent. In Brazil, records are still scarce, and further studies on this topic are needed. Objective - To evaluate the epidemiological profile and clinical characteristics of patients with IBD who were followed up at a reference service in the state of São Paulo. Methods - We retrospectively analyzed the medical records of patients with IBD who were followed up in a Brazilian Referral Center. Results - A total of 625 patients was evaluated, 416 with Crohn's disease (CD), 190 with ulcerative colitis (UC), and 19 with indeterminate colitis. The average age of the patients was 31.6 years, with a homogeneous distribution between males and females patients. In patients with CD, the most predominant Montreal classification was A2, L3, and B1, with $44.8 \%$ of patients presenting with perianal disease; in UC, it was E2, and S0. The main extraintestinal manifestation was rheumatologic, followed by cutaneous and ophthalmic lesions. The majority of patients ( $85.4 \%)$ used some type of medication, the most frequent being aminosalicylates in patients with UC and biological therapy in patients with CD. Regarding surgeries, in CD, a significant percentage of patients underwent some type of surgical procedure, unlike the UC patients, including fistulotomies and placement of seton, derivative ostomies, enterectomy, ileocecectomy/right colectomy, total or partial colectomy, and strictureplasty. Only $195(31.2 \%)$ patients lived in the city of Campinas, while 443 (70.9\%) were from the 7th Regional Health Department (RHD), which corresponds to the macro-region of Campinas. Conclusion - In this study, most patients came from the 7th RHD of Campinas; the patients were young, with no predominance of either sex; there was a higher frequency of patients with $\mathrm{CD}(66.6 \%)$. Most of them $(85.4 \%)$ were undergoing pharmacological treatment, and a significant percentage of CD patients had undergone surgery. Keywords - Crohn's disease; ulcerative colitis; epidemiology; gastrointestinal tract.

\section{INTRODUCTION}

Inflammatory bowel disease (IBD), most prominently represented by Crohn's disease (CD) and ulcerative colitis (UC), is a group of chronic diseases of the gastrointestinal tract (GIT). When the distinction between $\mathrm{CD}$ and $\mathrm{UC}$ is not possible, colitis is classified as indeterminate colitis (IC) $)^{(1)}$. All of these diseases are characterized by periods of activity and remission, and they affect mostly young individuals, with no predominance of $\operatorname{sex}^{(2,3)}$. UC affects the mucosal and submucosal layers of the colon and rectum, whereas $\mathrm{CD}$ can involve the entire GIT transmurally ${ }^{(4)}$. The phenotypes that characterize $\mathrm{CD}$ can be described as inflammatory (no stricturing no penetrating), stricturing, or penetrating, which are the three behaviors of the disease's presentation ${ }^{(5)}$. IBD corresponds to a group of immune-mediated diseases with a multifactorial etiology, and probably results from an interaction between genetic and environmental factors, which favors an uncontrolled immune response to the intestinal microbiota, causing tissue damage ${ }^{(6)}$.

The highest incidence and prevalence rates of IBD are mainly found in developed countries. In recent years, especially in the first two decades of the 21st century, an increase in IBD cases has been observed in newly industrialized and developing countries. This epidemiological change in newly industrialized countries is comparable to the patterns observed in Western developed countries more than 50 years ago ${ }^{(7)}$. Some factors may be responsible for this increased frequency of IBD in these countries, including a higher rate of urbanization that resulted in a transformation of lifestyle behaviors, higher rates of smoking, sedentary occupations, and lower rates of breastfeeding ${ }^{(8)}$.

In Brazil, where IBD is considered an emerging disease, there are only a few population-based studies. A justification for this is the lack of medical surveillance, reliable and unified records, and databases $^{(9,10)}$. Another factor that could explain this deficit is the disorganization of the health system in a country of continental size and its associated economic problems, which makes it difficult to maintain adequate records ${ }^{(10)}$. In addition, published epidemiological data can often be unreliable when measuring the real dimension of the problem, owing to the great heterogeneity of the characteristics presented in IBD, lack of access and availability of diagnostic methods, experience of the professionals involved, and information and notification systems in different regions of the country(11). 
A few studies have demonstrated an increase in incidence and prevalence rates of IBD in Brazil, confirming that IBD is a public health problem because of its chronicity, associated with high morbidity and treatment costs ${ }^{(12)}$. Therefore, this study aimed to assess the epidemiological profile and clinical characteristics of patients with IBD followed up at a Brazilian Referral Center by analyzing their sociodemographic characteristics, their stratification according to the Montreal classification, and by identifying the medical approach chosen for these patients.

\section{METHODS}

The study enrolled patients with CD, UC, and IC diagnosed at the IBD outpatient clinic, Prof. Dr. Juvenal Ricardo Navarro Góes, of the Center for Diagnosis of Diseases of the Digestive System (Gastrocenter), University of Campinas (Unicamp), and those who were treated between January 1991 and December 2019. The exclusion criteria were as follows: patients with other types of colitis, those under 18 years of age, those who missed follow-up, and deaths. Patient information was collected from the database of the outpatient clinic (attendance files and electronic registration). It was complemented, if necessary, with the medical records from the Unicamp Clinical Hospital, and more recently, with the hospital's electronic record system (AGHuse).

The variables collected and analyzed were sociodemographic characteristics (age, sex, city of origin, and the Regional Health Department [RHD]), clinical aspects (time of symptom onset until diagnosis, presence of extraintestinal manifestations (EIMs), the Montreal classification, personal history of smoking, and family history of IBD), and the performed treatment (medication and surgery). The Montreal classification was used to classify CD and $\mathrm{UC}$, and the parameters for $\mathrm{CD}$ were as follows: the age of the first clinical presentation of the disease $(\mathrm{A}=$ age $)$, the location of the involvement in the GIT ( $\mathrm{L}=$ location), and the clinical behavior of the disease ( $\mathrm{B}=$ behavior). For $\mathrm{UC}$, it was based on the endoscopic appearance of the colon (remission, mild, moderate, or severe disease), and the maximum extent of intestinal involvement (distal, left colitis, or pancolitis) observed during the colonoscopy exam ${ }^{(13)}$.

The study was approved by the Research Ethics Committee of the Faculty of the University of Campinas (Unicamp) under the registered approval number 3,265,851 (CAAE: 02165318.2.0000.5404), and was conducted in accordance with the declaration of Helsinki. The data were plotted in an Excel spreadsheet and statistical analysis was performed using the Statistical Package for Social Sciences program version 25.0 (SPSS Inc., Chicago, IL, USA, 2018). The results are presented using descriptive statistics, using absolute and relative distributions (\%), and measures of central tendency (mean and median), and variability (standard deviation, amplitude, and interquartile amplitude), with the study of the symmetry of distributions using the Kolmogorov-Smirnov test.

\section{RESULTS}

During the study period, 1,231 patients were treated at the IBD outpatient clinic. Of these, 574 missed the follow-up appointments over the years. There were 28 deaths, 14 of which were due to disease-related causes; four were excluded from the study because they were underage. Thus, the study population comprised 625 patients, of which $416(66.6 \%)$ had CD, $190(30.4 \%)$ had UC, and $19(3.0 \%)$ had IC (FIGURE 1).

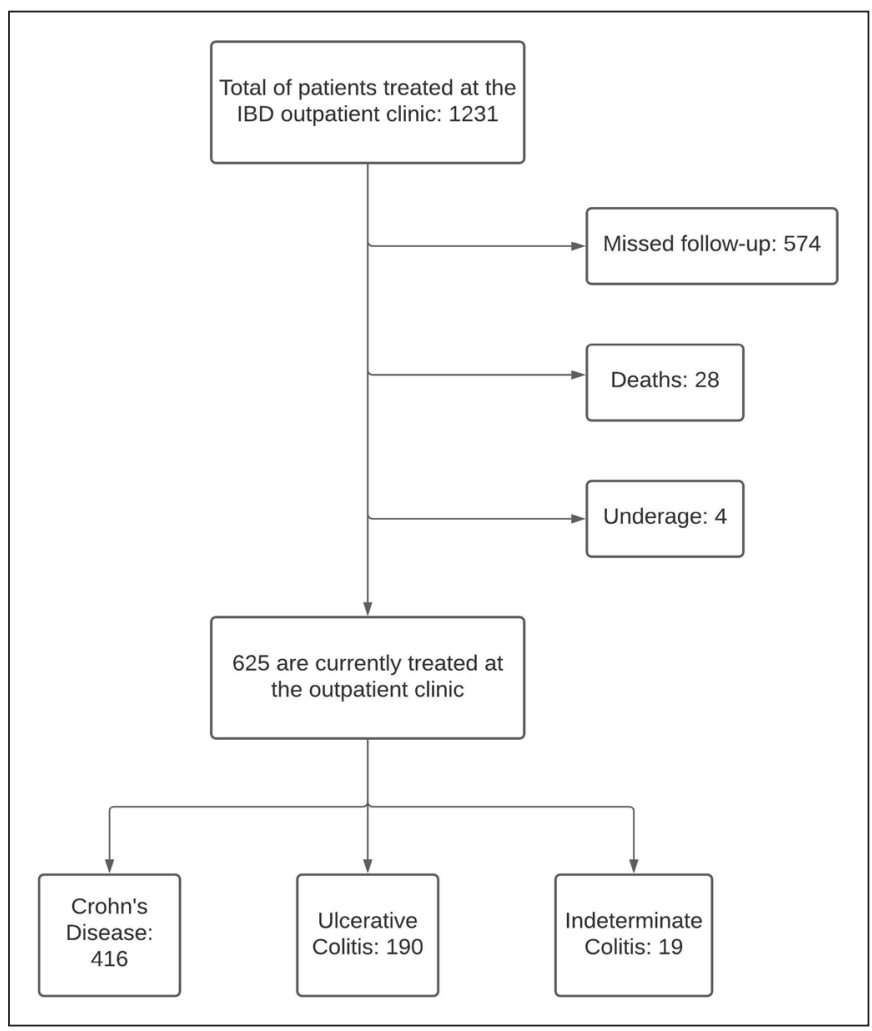

FIGURE 1. Population included in the study.

IBD: inflammatory bowel disease.

The outpatient clinic of GASTROCENTER-Unicamp is a reference center for IBD treatment for the 7th RHD, which covers 43 municipalities around Campinas, in São Paulo state, Brazil (TABLE 1).

The population of this region is 4,008,065 inhabitants, According to the latest census of 2010 (Brazilian Institute of Geography and Statistics, 2020). The prevalence of IBD in the 7th RHD was 15.59/100,000 inhabitants, of which 10.38/100,000 inhabitants had CD and 4.74/100,000 inhabitants had UC. Although the majority of patients come from this RHD, some hail from other distant regions, and even from other states, mainly cities in the South of Minas Gerais (TABLE 2).

Regarding the patients' current age, the mean and median for $\mathrm{CD}, \mathrm{UC}$, and IC were $44.98(\mathrm{SD}=14.3)$ and 44 years; 50.35 $(\mathrm{SD}=15.5)$ and 52 years; and $45.16(\mathrm{SD}=17.0)$ and 39 years, respectively. Of the 362 patients with CD in whom information on family history of IBD was obtained, 38 patients had a family history of IBD. Among the $161 \mathrm{UC}$ patients, 18 presented the same history. Furthermore, 52 of 203 patients with CD; and 16 of the 79 patients with UC had a history of smoking (TABLE 3 ).

The age at the time of IBD diagnosis ranged from 7 to 78 years, with a mean of 31.62 years $(S D=13.2)$. The mean age for $C D$ was 29.61 years $(\mathrm{SD}=12.0)$, ranging from 7 to 73 years, and for $\mathrm{UC}$, 35.79 years $(\mathrm{SD}=14.3)$, ranging from 10 to 78 years.

According to the Montreal classification for CD, there was a higher frequency of the A2 age Group (72.8\%), with a similar distribution between males and females. The L3 location (34.4\%) and B1 behavior (46.9\%) were observed. Approximately half of the patients $(44.5 \%)$ had an association with perianal disease (TABLE 4). 
TABLE 1. Distribution of patients according to the city of origin ( 7 th Regional Health Department) and its population.

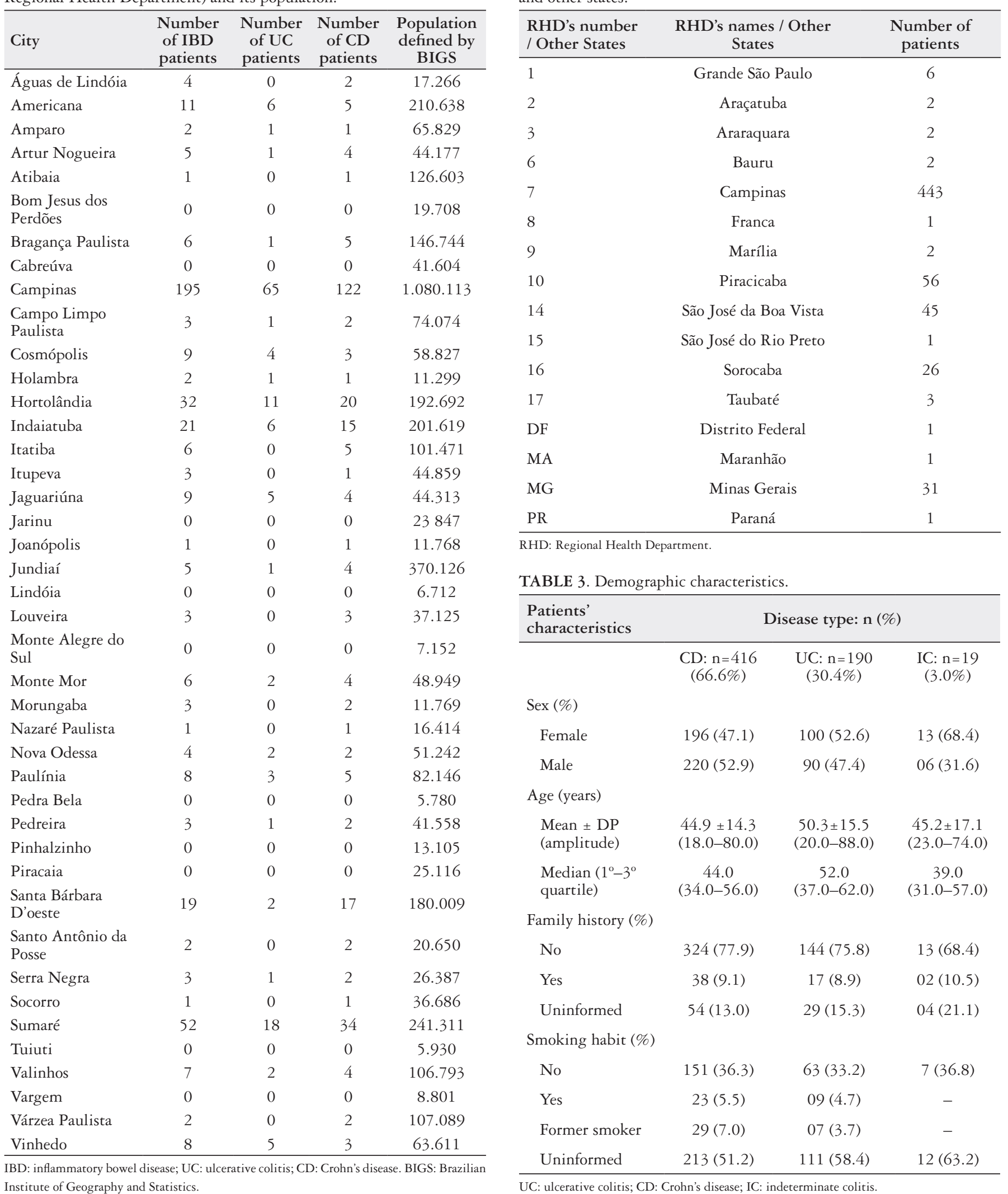

TABLE 2. Distribution of patients according to RHDs in São Paulo State and other states.

TABLE 3. Demographic characteristics. 
TABLE 4. Montreal classification for Crohn's disease.

\begin{tabular}{|c|c|c|c|}
\hline \multirow[b]{2}{*}{ Characteristics } & \multirow[b]{2}{*}{$\begin{array}{c}\text { Total of } \\
\text { patients } \\
n=416\end{array}$} & \multicolumn{2}{|c|}{ Sex } \\
\hline & & $\begin{array}{c}\text { Female } \\
n=196 \\
(47.1 \%)\end{array}$ & $\begin{array}{c}\text { Male } \\
\mathrm{n}=220 \\
(52.9 \%)\end{array}$ \\
\hline \multicolumn{4}{|c|}{ Age at the diagnostic (A) } \\
\hline$A 1: \leq 16$ years & $45(10.8)$ & $17(8.7)$ & $28(12.7)$ \\
\hline A2: $17-40$ years & $303(72.8)$ & $146(74.5)$ & $157(71.4)$ \\
\hline A3: $>40$ years & $68(16.4)$ & $33(16.8)$ & $35(15.9)$ \\
\hline \multicolumn{4}{|l|}{ Location (L) } \\
\hline L1: Terminal ileum & $139(33.4)$ & $59(30.1)$ & $80(36.4)$ \\
\hline L2: Colon & $131(31.5)$ & $65(33.2)$ & $66(30.0)$ \\
\hline L3: Ileocolon & $143(34.4)$ & $71(36.2)$ & $72(32.7)$ \\
\hline L4: Upper GI & $03(0.7)$ & $01(0.5)$ & $02(0.9)$ \\
\hline \multicolumn{4}{|l|}{ Behavior (B) } \\
\hline B1: Inflammatory & $195(46.9)$ & $90(45.9)$ & $105(47.7)$ \\
\hline B2: Stricturing & $99(23.8)$ & $49(25.0)$ & $50(22.7)$ \\
\hline B3: Penetrating & $122(29.3)$ & $57(29.1)$ & $65(29.6)$ \\
\hline \multicolumn{4}{|c|}{$\begin{array}{l}\text { Perianal disease modifier } \\
(\mathrm{P})\end{array}$} \\
\hline Yes & $185(44.5)$ & $90(45.9)$ & $95(43.2)$ \\
\hline No & $231(55.5)$ & $106(54.1)$ & $125(56.8)$ \\
\hline
\end{tabular}

GI: gastrointestinal.

Regarding UC, the predominant extension was E2 (left-sided colitis), followed by E3 (pancolitis), with a prevalence of $50.5 \%$ and $45.8 \%$, respectively. Concerning the severity of the disease, most patients were in remission (S0, 87.9\%) (TABLE 5).

TABLE 5. Montreal classification for ulcerative colitis.

\begin{tabular}{lccc}
\hline & \begin{tabular}{c} 
Total of \\
patients \\
\cline { 3 - 4 } Characteristics
\end{tabular} & $\begin{array}{c}\text { Female } \\
\mathbf{n}=100 \\
(52.6 \%)\end{array}$ & $\begin{array}{c}\text { Male } \mathbf{n = 9 0} \\
(47.4 \%)\end{array}$ \\
\hline Disease extent (E) & & & \\
E1: Proctitis & $07(3.7)$ & $03(3.0)$ & $04(4.4)$ \\
E2: Left-sided colitis & $96(50.5)$ & $55(55.0)$ & $41(45.6)$ \\
E3: Pancolitis & $87(45.8)$ & $42(42.0)$ & $45(50.0)$ \\
Severity (S) & & & $76(84.5)$ \\
S0: Clinical remission & $167(87.9)$ & $91(91.0)$ & $11(12.2)$ \\
S1: Mild UC & $18(9.5)$ & $07(7.0)$ & $03(3.3)$ \\
S2: Moderate UC & $04(2.1)$ & $01(1.0)$ & - \\
S3: Severe UC & $01(0.5)$ & $01(1.0)$ & \\
\hline
\end{tabular}

UC: ulcerative colitis.

It was possible to verify in 547 medical records the elapsed time between the onset of symptoms and diagnosis of IBD. Among them, in case of five patients it took more than 20 years to establish the correct diagnosis of IBD. Twenty-nine $(5.3 \%)$ patients had their diagnoses between 11 and 20 years; $67(12.2 \%)$ between 6 and 10 years; $123(22.5 \%)$ between 2 and 5 years; and $323(59.0 \%)$ with less than 2 years after the onset of symptoms. Regarding the IBD EIMs, these were observed in 219 patients, the most frequent being rheumatological diseases, represented by arthritis, arthralgia, and ankylosing spondyloarthritis, which were present in $174(79.4 \%)$ patients, with a prevalence of $57.1 \%$ in patients with CD and $21.0 \%$ in patients with UC. Subsequently, dermatological and ophthalmological manifestations were observed. Primary sclerosing cholangitis was present in 10 patients, six with UC and four with CD.

Regarding the use of medications, $85.4 \%$ of the patients were under pharmacological therapy. Biological therapies and thiopurines for CD and aminosalicylates for UC are the most common. For patients undergoing biological therapy, 55.3\% were on combined immunosuppressive therapy $(\mathrm{CD}=46.4 \%$; $\mathrm{UC}=8.9 \%)$. Among the previously used drugs, the most frequent were aminosalicylates $(72.5 \%)$. Furthermore, $4.1 \%$ of the patients used more than one biological therapy during the course of treatment (TABLE 6).

TABLE 6. Pharmacological treatment of inflammatory bowel diseases patients followed-up at Clinical Hospital of the University of Campinas.

\begin{tabular}{lcccc}
\hline \multirow{2}{*}{ Characteristics } & \multirow{2}{*}{\begin{tabular}{c} 
Total \\
\cline { 3 - 4 }
\end{tabular}} & $\mathbf{n}=625$ & CD: $\mathbf{n}=416$ & UC: $\mathbf{n}=190$ \\
\hline Current medications & & & \\
No & $91(14.6)$ & $65(15.6)$ & $22(11.6)$ \\
Yes & $534(85.4)$ & $351(84.4)$ & $168(88.4)$
\end{tabular}

Current medications

$\begin{array}{lccc}\text { Aminosalicylates } & 149 & 38 & 106 \\ \text { Thiopurines } & 284 & 217 & 59 \\ \text { Methotrexate } & 16 & 13 & 03 \\ \text { Biological* } & 338 & 265 & 66\end{array}$

Previous medications

$\begin{array}{lccc}\text { Aminosalicylates } & 454 & 280 & 162 \\ \text { Thiopurines } & 327 & 245 & 70 \\ \text { Methotrexate } & 32 & 29 & 03 \\ \text { Biological } & 205 & 169 & 31 \\ \text { More than one biological } & 26 & 20 & 06\end{array}$

IBD: inflammatory bowel disease; UC: ulcerative colitis; CD: Crohn's disease.

*Combination therapy (immunosuppressant + biological) in 157 with CD and 30 with UC.

Concerning surgeries, only seven patients with UC underwent surgical procedures in other services, while 157 patients with CD had already undergone previous surgeries. In our IBD unit, 35 patients with UC underwent surgical procedures (FIGURE 2), ileal pouch-anal anastomosis in $17(8.9 \%)$ patients, total colectomy and rectal closure with terminal ileostomy in $8(4.2 \%)$ patients, and ileorectal anastomosis in $6(3.1 \%)$ patients. All patients who underwent ileal pouch surgery and two patients with ileorectal anastomosis also had protective ileostomy, which was later closed. Regarding $\mathrm{CD}, 251$ patients required surgery at our IBD unit (FIGURE 2), of which perianal procedures were the most frequently performed. Among the abdominal surgeries, the most commonly performed procedures were enterectomy and ileocectomy/right colectomy. In addition, several patients required more than one surgery, both abdominal and perianal procedures. 


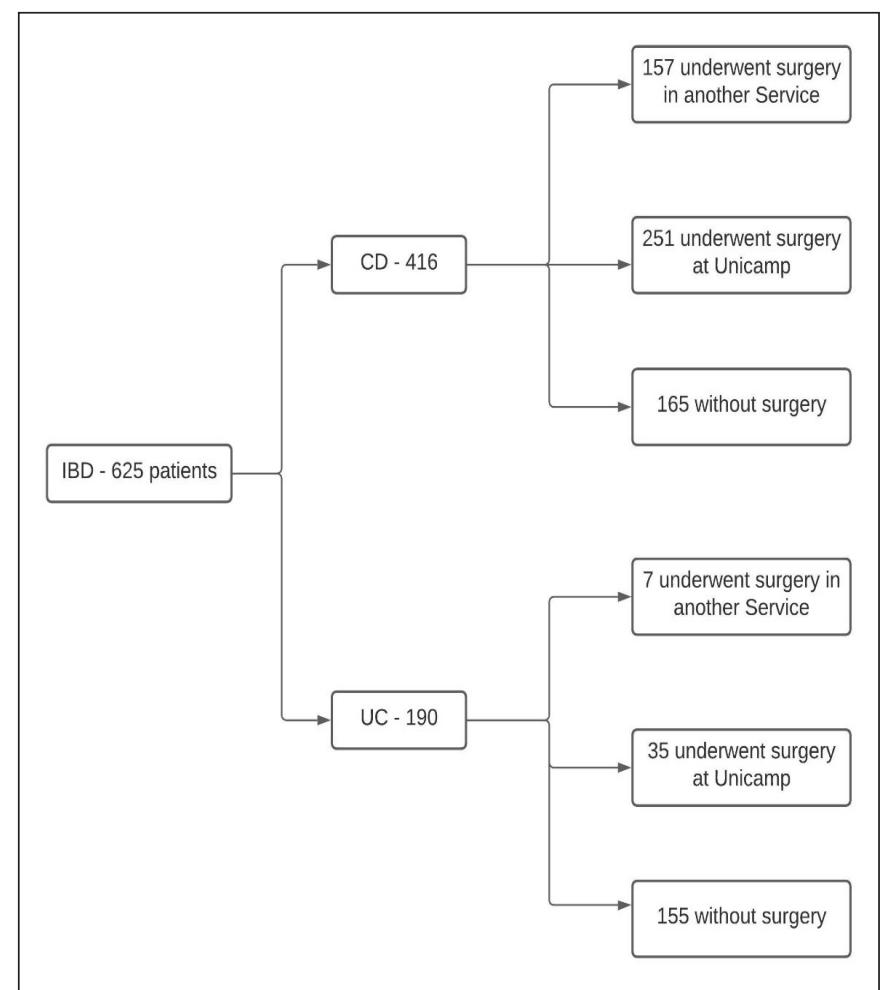

FIGURE 2. Total number of patients previously submitted to surgery in other services and in the Clinical Hospital of Unicamp.

CD: Crohn's disease; IBD: inflammatory bowel disease; UC: ulcerative colitis.

\section{DISCUSSION}

Incidence/prevalence: the prevalence of IBD is increasing worldwide. Several studies have sought to identify its origin and factors that in combination lead to its development. IBD results from the interaction between environmental and epigenetic factors, which are not completely known, in predisposed individuals ${ }^{(14)}$.

Until the middle of the 20th century, IBD was found mainly in developed countries in North America, Europe, and Oceania. Further, its incidence increased in newly industrialized countries in Asia, South America, and Africa, especially in the 21 st century ${ }^{(7,15)}$. The highest incidence and prevalence rates were found in the most economically developed countries, as in Northern Europe, Canada, the United States, Australia, and New Zealand ${ }^{(16-19)}$.

The present study is justified by the lack of data on the clinical and demographic characteristics of the Brazilian population, especially in the heartland of São Paulo state. In our study, most of the patients came from the macro-region of Campinas, while $29.2 \%$ belonged to other RHDs or even other states. The 7th RHD is composed of 43 municipalities in the Campinas region; thus, presenting an estimated IBD prevalence of 15.59 cases/100,000 inhabitants and an estimated CD prevalence of 10.38/100,000 inhabitants. This prevalence is estimated and not absolute, as not all diagnosed patients use our service. In similar studies, Victoria et al. ${ }^{(20)}$ and Lima-Martins et al. ${ }^{(21)}$ observed an estimated CD prevalence of 5.7/100,000 and $14.1 / 100,000$ inhabitants, respectively. The estimated prevalence of UC was 4.74/100,000 inhabitants, which is lower than that in the study of these two authors, which was 15/100,000 inhabitants and 24.1/100,000 inhabitants, respectively ${ }^{(20,21)}$.
Brazilian and international population studies have demonstrated a higher prevalence rate of UC compared to $\mathrm{CD}^{(20,22,23)}$. Victoria et al. ${ }^{(20)}$ reported that UC represented $65.2 \%$ of the diagnoses and $25.2 \%$ of $\mathrm{CD}$, while Lima-Martins et al. ${ }^{(21)}$ reported prevalence rates of $63 \%$ and $37 \%$, respectively. In contrast to these findings, some studies in IBD reference centers in Brazil have observed the opposite: Parente et al. ${ }^{(24)}$ demonstrated a higher prevalence of $\mathrm{CD}$ in relation to UC $(60.3 \%$ vs $39.7 \%)$ in the Piaui state and Santos et al. ${ }^{(25)}$ in Rio de Janeiro (56.4\% vs $38.3 \%$ ), as observed in our study. The follow-up of CD is generally more complex, requiring more frequent therapeutic adjustments to keep the patient in remission, so it is expected that these patients will be referred more regularly to a specialized center, which explains the higher frequency of $\mathrm{CD}$ in these units.

In addition to the data on the incidence and prevalence of $\mathrm{CD}$ and UC, other factors that contribute to this are the lack of patients' records in the private service and the fact that reporting IBD is not mandatory ${ }^{(10)}$. Five Brazilian studies that focused on IBD have been published, three in the São Paulo state ${ }^{(9,20,26)}$, one in the Piaui state ${ }^{(24)}$, and another in the Espirito Santo state ${ }^{(21)}$, covering the period from 1986 to 2015 . All of these studies were retrospective, with variations in the severity of the patients included, as well as the location of data collection, its scope, type of database used, and form of access to the health system, whether public or private. Although these studies are not comparable owning to their different methodologies, there was a variation in the incidence rate of CD from 3.50 to $6.14 / 100,000$ inhabitants and UC from 2.40 to $7.16 / 100,000$ inhabitants, which demonstrates a chronological increase in the incidence of $\operatorname{IBD}^{(9,20,21,24,26)}$.

Selvaratnan et al. ${ }^{(27)}$ in a systematic review involving six studies (three from Brazil, one from Argentina, one from Colombia, and one from Uruguay), described the incidence of IBD in South America, a significantly higher incidence of UC than of $\mathrm{CD}$ was reported. A female predominance, which was not statistically significant, for both $\mathrm{UC}$ and $\mathrm{CD}$, was demonstrated in most of these studies. There was also a predominance of colonic CD and pancolonic UC. This finding may be associated with differences in genetic polymorphisms or environmental exposure. However, the potential for divergence due to problems, such as notification of the disease, also needs to be considered. Colonic CD and pancolonic UC are generally more symptomatic. Therefore, they are more likely to be reported when compared to CD that involves the small intestine or less extended $\mathrm{UC}$, which is prone to underreporting or misdiagnosis, particularly in the most disadvantaged regions.

$\mathrm{Ng}$ et al. ${ }^{(7)}$ in a systematic review involving 119 studies of incidence and 69 of prevalence of IBD observed that most studies showed stability or decrease in incidence in the most prevalent areas, however this incidence remains high. This study also demonstrated that the incidence of IBD was increasing in countries in Africa, Asia, and South America, including Brazil. The current incidence and prevalence rates reported in recently industrialized countries are similar to those reported in Western developed countries 50 years ago.

Symptoms/time for the diagnosis: another important factor is the time interval that some patients require from the beginning of the symptoms until the definitive diagnosis is established and adequate treatment is initiated. In this study, five patients required more than 20 years for their diagnoses, and 29 required more than 10 years. These data are important to highlight that these diseases have often been underreported and are neglected. However, the di- 
agnosis can be difficult, especially if the symptoms are nonspecific, and the correct diagnosis and treatment plan are essential to avoid the complications of the disease over the years.

Both CD and UC are diseases that manifest themselves in young individuals, which increases the need to request adequate monitoring to minimize the negative impacts that can occur in the social and professional lives of the patients ${ }^{(12)}$. In this study, IBD was found in all ages, but it was most often found between 20 and 25 years of age. These data are similar to those of previously published studies that highlight the age between 15 and 40 years for the occurence of IBD $^{(24-26,28)}$. When assessing the age at diagnosis of patients with IBD separately, CD presents only one peak in the age group, unlike the UC, where a second peak is observed between 40 and 44 years of age ${ }^{(28)}$. The results found in our study were similar to those already published in the literature, which present the age at the time of diagnosis as bimodal profile, a peak in the young adult, and a second peak in older individuals ${ }^{(21,29,30)}$. Regarding gender distribution, most studies did not show statistical differences between men and women ${ }^{(21,31)}$, as confirmed in our data. When diseases were analyzed separately, there was a slight female predominance for UC and a male predominance for CD, similar to the findings of Ooi et al. in $\mathrm{Asia}^{(28)}$.

Family history and smoking habits: regarding the occurrence of IBD in individuals of the same family, our study demonstrated that approximately $10 \%$ had a family history of IBD, values higher than those found by Torres et al. ${ }^{(26)}$, who observed a family history rate in only $2 \%$ of patients. These numbers may be underestimated because in a wide country like Brazil, many patients do not have this information or even have no contact with their family. The association between smoking habit and IBD is well established and smoking is a risk factor for $\mathrm{CD}$ and a protector for $\mathrm{UC}$, especially in severe forms ${ }^{(8,32,33)}$. The etiology of these associations is not yet well established, and it is not known whether this relationship is local (nicotine and intestine) or systemic ${ }^{(34)}$. In this study, this information was partially impaired, as approximately $50 \%$ of medical records lacked documented data. Based on the other cases, approximately a quarter of the patients were smokers or former smokers ${ }^{(7,8,34)}$.

Extraintestinal manifestations: one of the characteristics of IBD is the occurrence of manifestations of the disease outside the GIT, the EIMs. Articular manifestations are the most commonly found, followed by dermatological manifestations ${ }^{(35)}$, similar to our findings. Some European studies have indicated the presence of EIMs in $20-40 \%$ patients with CD and $15-20 \%$ patients with UC. D'Inca et al. ${ }^{(36)}$ after a 1-year follow-up found that joint symptoms were observed in $45.1 \%$ of patients with CD and $36.9 \%$ of patients with UC. Skin or dermatological lesions are the second most common type of EIMs, with erythema nodosum, pyoderma gangrenosum, and aphthous stomatitis ${ }^{(35)}$. The frequency of dermatological EIMs in Hungary was $5-15 \%$ in CD, with a female predominance and patients with active disease ${ }^{(16,35)}$. Another study that analyzed this factor was a French cohort with 2,402 patients with IBD, of which $5.6 \%$ had erythema nodosum and $0.75 \%$ had pyoderma gangrenosum $^{(37)}$. Lastly, eye manifestations were the third most frequent EIMs found in our study, for both CD and UC, in accordance with data from the international literature, such as the findings of Lakatos et al. ${ }^{(35)}$, who reported a prevalence of $3 \%$ for $\mathrm{CD}$ and $6 \%$ for UC.

Classification: the Montreal classification is the most commonly used classification for IBD. To select the best therapeutic approach and most appropriate follow-up for each patient, it is important to correlate specific disease phenotypes with possible clinical and prognostic outcomes. CD considers the following parameters: age at clinical presentation, location of the disease, and clinical behavior ${ }^{(38)}$. Regarding the location of ileal (L1), colonic (L2), and ileocolonic (L3) disease, the frequency of involvement observed was similar to that reported in the literature ${ }^{(16)}$ and in the Brazilian study by Lima-Martins et al. ${ }^{(21)}$. For upper GIT disease (L4), there was a variation between $10 \%$ and $15 \% 0^{(39,40)}$, and LimaMartins et al. ${ }^{(21)}$ observed $8 \%$ higher values than this study. This occurred mainly because we considered L4 patients who had only upper GIT involvement. We also observed a higher frequency of the inflammatory form (B1), corroborating the data obtained by Lima-Martins et al. ${ }^{(21)}$, whose study showed $57.7 \%$ of patients with this classification. We found $44.5 \%$ of perianal involvement, data similar to the studies by Lima-Martins et al. ${ }^{(21)}$ and Parente et al. ${ }^{(24)}$. However, in other demographic studies, the rate of perianal disease ranged between $10 \%$ and $18 \% \%^{(23,41)}$

In these reference centers, the services are coordinated by colorectal surgeons and the patients receive referrals with surgical treatment proposals. Most patients with perianal disease undergo surgical exploration of the perineum with combined clinical therapy.

Regarding UC, the Montreal classification includes the extent and severity of the disease. In this study, the most frequent location was left-sided colitis, followed by pancolitis. Proctitis was rare, as in other studies in the literature ${ }^{(20,21,26)}$. The low percentage of patients with proctitis is probably because many of these patients are oligosymptomatic and are treated by physicians who are not IBD specialists. Regarding the severity of the disease, the vast majority of patients were in remission, as in the study by Silva et al. ${ }^{(33)}$, who reported $45.7 \%$ of patients in remission, differing from the findings by Parente et al. ${ }^{(24)}$, who had a predominance of patients with moderate disease.

Clinical/surgical treatment: aminosalicylates have been the most widely used class of medication over the years (approximately $72.5 \%$ of patients in this study used this drug). Currently, only $23.8 \%$ of patients are using this medication. When diseases are analyzed separately, only $9.1 \%$ patients with CD use aminosalicylates, while $55.8 \%$ patients with UC are under this medication. These data are in accordance with the current management guidelines ${ }^{(16)}$. Immunosuppressants, represented by thiopurines and methotrexate, are used mainly in combination therapy with biological therapies to reduce the formation of anti-drug antibodies ${ }^{(42)}$. In our study, 55.3\% of the patients who used biological drugs maintained combination therapy. In the Brazilian Unified Health System Service, only anti-tumor necrosis factor- $\alpha$ monoclonal antibodies (infliximab, adalimumab, and certolizumab pegol) were available. Nonetheless, more than half of our patients with $\mathrm{CD}$ and approximately onethird of patients with UC were using this class of drugs. These data are superior to those described by Lima-Martins et al. ${ }^{(21)}$.

The rates of patients requiring surgery for $C D$ are higher than for UC. In our CD cohort, more than half of the patients underwent surgery, which was performed both in our hospital and previously in other services, values much higher than those reported by Bernstein et al. ${ }^{(43)}$ and Bechara et al. ${ }^{(44)}$, who observed the rate of surgery ranging from $12 \%$ to $26.7 \%$. Regarding UC, $18.4 \%$ of our patients had underwent surgery, and the numbers were higher than those found in the literature ${ }^{(44,45)}$. As mentioned before, these findings are justified because it is an outpatient clinic coordinated by colorectal surgeons, where patients are mostly referred for the purpose of surgical evaluation. 
The main limitation of the present study was its retrospective nature, which led to the lack of clinical data, in addition to the inclusion of patients from only a single center. However, further studies must be performed in different regions of Brazil to have a broader view of IBD epidemiology among Brazilian population and to create better strategies to deal with this relevant chronic disease.

\section{CONCLUSION}

Most of the patients belonged to the 7th RHD of Campinas. There was a predominance of patients with $\mathrm{CD}$, young age, and disease onset in the third decade of life. In general, there was no predominance of sex, but more women with UC and men with $\mathrm{CD}$ were observed. There was an equivalence of distribution between the locations $(\mathrm{L} 1=\mathrm{L} 2=\mathrm{L} 3)$ and a predominance of inflammatory behavior (B1), with almost half of the patients showing perianal involvement in $\mathrm{CD}$ patients. In $\mathrm{UC}$, the most common phenotype was left-sided colitis (E2), and most patients had been in remission (S0). Aminosalicylates have been the most widely used drugs over the years, with biological therapy being the most commonly used. More than half of the patients with CD underwent surgical procedures, unlike UC patients who were treated mostly by pharmacological therapy.

\section{ACKNOWLEDGEMENTS}

We thank Professor Tristan Torriani for the English revision of our manuscript and Editage (www.editage.com.br) for English language editing.

\section{Authors' contribution}

Fucilini LMP: data collection, statistical analysis, data interpretation, writing of the manuscript. Genaro LM: data collection, data interpretation, writing of the manuscript. Souza DC: data collection. Coy CSR: final revision of manuscript. Leal RF: planning of the study, design study, manuscript concept, data interpretation, and final revision of manuscript. Ayrizono MLS: planning of the study, design study, manuscript concept, data interpretation, writing and final revision of manuscript.

\section{Orcid}

Luiza Maria Pilau Fucilini: 0000-0001-5475-2230.

Lívia Moreira Genaro: 0000-0002-4640-6554.

Daniela Cunha e Sousa: 0000-0002-3395-2038.

Cláudio Saddy Rodrigues Coy: 0000-0002-0916-4138.

Raquel Franco Leal: 0000-0003-4285-4402.

Maria de Lourdes Setsuko Ayrizono: 0000-0002-7035-2568.

Fucilini LMP, Genaro LM, Sousa DC, Coy CSR, Leal RF, Ayrizono MLS. Perfil epidemiológico e características clínicas das doenças inflamatórias intestinais em um centro de referência Brasileiro. Arq Gastroenterol. 2021;58(4):483-90.

RESUMO - Contexto - O aumento na incidência e prevalência das doenças inflamatórias intestinais (DIIs) é evidente em muitos países recém-industrializados da Ásia, África, Europa Oriental e do continente Americano. No Brasil, os registros ainda são bastante escassos, sendo necessários mais estudos sobre este tema. Objetivo - Avaliar o perfil epidemiológico e as características clínicas dos doentes com DIIs, acompanhados em um serviço de referência no Estado de São Paulo. Métodos - Análise retrospectiva, descritiva, dos prontuários médicos dos pacientes com DIIs acompanhados em um centro de referência no Brasil. Resultados - Foram avaliados 625 doentes, sendo 416 com doença de Crohn (DC), 190 com retocolite ulcerativa (RCU) e 19 com colite indeterminada. A média de idade foi de 31,6 anos, sendo a distribuição homogênea entre os sexos. Na DC predominou a classificação de Montreal A2 L3 e B1, com 44,8\% dos doentes apresentando doença perianal; na RCU, E2 e S0. A principal manifestação extraintestinal presente foi reumatológica, vindo a seguir as lesões cutâneas e as oftalmológicas. A maioria dos doentes $(85,4 \%)$ fazia uso de alguma medicação, sendo as mais frequentes, aminossalicilatos na RCU e terapia biológica na DC. Em relação às cirurgias, na DC um significativo percentual de pacientes foi submetido a algum tipo de procedimento cirúrgico, ao contrário da RCU, incluindo fistulotomias e colocação de sedenhos, estomas de derivação, enterectomia, ileotiflectomia/colectomia direita, colectomia total ou parcial e plastias intestinais. Apenas 195 (31,2\%) doentes eram da cidade de Campinas, mas $443(70,9 \%)$ eram provenientes do $7^{\circ}$ Departamento Regional de Saúde (DRS), que corresponde a Grande Campinas. Conclusão - No estudo, houve um predomínio de pacientes do DRS de Campinas; os doentes eram jovens, sem predominância de sexo; a frequência maior foi de doentes com DC $(66,6 \%)$. A maioria $(85,4 \%)$ estava em tratamento farmacológico, e um percentual significativo de doentes com DC, havia sido submetido à cirurgia.

Palavras-chave - Doença de Crohn; retocolite ulcerativa; epidemiologia; trato gastrointestinal.

\section{REFERENCES}

1. Nikolaus S, Schreiber S. Diagnostics of inflammatory bowel disease. Gastroenterology. 2007;133:1670-89.

2. Ramos GP, Papadakis KA. Mechanisms of Disease: Inflammatory Bowel Diseases. Mayo Clin Proc. 2019;94:155-65.

3. Cardozo WS, Sobrado CW. Doença Inflamatória Intestinal. 2a Edição ed. São Paulo SP 2015

4. Mulder DJ, Noble AJ, Justinich CJ, Duffin JM. A tale of two diseases: the history of inflammatory bowel disease. J Crohns Colitis. 2014;8:341-8.

5. Baumgart DC. The diagnosis and treatment of Crohn's disease and ulcerative colitis. Dtsch Arztebl Int. 2009;106:123-33.

6. Vasconcelos RS, Rocha RM, Souza EB, Amaral VRS. Life quality of patients with inflammatory bowel disease: integrative review Calidad de vida de pacientes con enfermedad inflamatoria intestinal: revisión integrativa. [Article in Portuguese]. ESTIMA, Braz J Enterostomal Ther. 2018;16. doi: 10.30886/estima. v16.480_PT
7. Ng SC, Shi HY, Hamidi N, Underwood FE, Tang W, Benchimol EI, et al. Worldwide incidence and prevalence of inflammatory bowel disease in the 21 st century: a systematic review of population-based studies. Lancet. 2018;390:2769-78.

8. Vedamurthy A, Ananthakrishnan AN. Influence of Environmental Factors in the Development and Outcomes of Inflammatory Bowel Disease. Gastroenterol Hepatol (NY). 2019;15:72-82.

9. Gasparini RG, Sassaki LY, Saad-Hossne R. Inflammatory bowel disease epidemiology in São Paulo State, Brazil. Clin Exp Gastroenterol. 2018;11:423-9.

10. Quaresma AB, Kaplan GG, Kotze PG. The globalization of inflammatory bowel disease: the incidence and prevalence of inflammatory bowel disease in Brazil. Curr Opin Gastroenterol. 2019;35:259-64.

11. Bernstein CN, Shanahan F. Disorders of a modern lifestyle: reconciling the epidemiology of inflammatory bowel diseases. Gut. 2008;57:1185-91.

12. Kaplan GG, Ng SC. Understanding and Preventing the Global Increase of Inflammatory Bowel Disease. Gastroenterology. 2017;152:313-21.e2. 
13. Silverberg MS, Satsangi J, Ahmad T, Arnott ID, Bernstein CN, Brant SR, et al. Toward an integrated clinical, molecular and serological classification of inflammatory bowel disease: report of a Working Party of the 2005 Montreal World Congress of Gastroenterology. Can J Gastroenterol. 2005;19 (Suppl A): 5A-36A.

14. Queiroz DM, Oliveira AG, Saraiva IE, Rocha GA, Rocha AM, das Graças Pimenta Sanna M, et al. Immune response and gene polymorphism profiles in Crohn's disease and ulcerative colitis. Inflamm Bowel Dis. 2009;15:353-8.

15. Buenavida G, Casañias A, Vásquez C, De Souza M, Martínez L, Gardil I, et al. Incidence of inflammatory bowel disease in five geographical areas of Uruguay in the biennial 2007-2008. Acta Gastroenterol Latinoam. 2011;41:281-7.

16. Burisch J, Jess T, Martinato M, Lakatos PL, EpiCom E. The burden of inflammatory bowel disease in Europe. J Crohns Colitis. 2013;7:322-37.

17. Lophaven SN, Lynge E, Burisch J. The incidence of inflammatory bowel disease in Denmark 1980-2013: a nationwide cohort study. Aliment Pharmacol Ther 2017:45:961-72.

18. Kaplan GG, Bernstein CN, Coward S, Bitton A, Murthy SK, Nguyen GC, et al The Impact of Inflammatory Bowel Disease in Canada 2018: Epidemiology. J Can Assoc Gastroenterol. 2019;2(Suppl 1):S6-S16.

19. Studd C, Cameron G, Beswick L, Knight R, Hair C, McNeil J, et al. Never underestimate inflammatory bowel disease: High prevalence rates and confirmation of high incidence rates in Australia. J Gastroenterol Hepatol. 2016; 31:81-6.

20. Victoria CR, Sassak LY, Nunes HR. Incidence and prevalence rates of inflammatory bowel diseases, in midwestern of São Paulo State, Brazil. Arq Gastroenterol. 2009;46:20-5.

21. Lima Martins A, Volpato RA, Zago-Gomes MDP. The prevalence and phenotype in Brazilian patients with inflammatory bowel disease. BMC Gastroenterol 2018;18:87.

22. Simian D, Fluxá D, Flores L, Lubascher J, Ibáñez P, Figueroa C, et al. Inflammatory bowel disease: A descriptive study of 716 local Chilean patients. World J Gastroenterol. 2016;22:5267-75.

23. Burisch J, Pedersen N, Čuković-Čavka S, Brinar M, Kaimakliotis I, Duricova $\mathrm{D}$, et al. East-West gradient in the incidence of inflammatory bowel disease in Europe: the ECCO-EpiCom inception cohort. Gut. 2014;63:588-97.

24. Parente JM, Coy CS, Campelo V, Parente MP, Costa LA, da Silva RM, et al Inflammatory bowel disease in an underdeveloped region of Northeastern Brazil. World J Gastroenterol. 2015;21:1197-206.

25. Santos RMD, Carvalho ATP, Silva KDS, Sá SPC, Santos AHD, Sandinha MR Inflammatory Bowel Disease: Outpatient Treatment Profile. Arq Gastroenterol. 2017;54:96-100

26. Torres US, Rodrigues JO, Junqueira MS, Uezato S, Netinho JG. The Montreal Classification for Crohn's disease: clinical application to a Brazilian single-center cohort of 90 consecutive patients. Arq Gastroenterol. 2010;47:279-84.

27. Selvaratnan S, Gullino S, Shim L, Lee E, Lee A, Paramsothy S. Epidemiology of inflammatory bowel disease in South America: A systematic review. World J Gastroenterol. 2019;25:6866-75.

28. Ooi CJ, Makharia G, Hilmi I, Gibson P, Fock KM, Ahuja V. Asia Pacific Consensus Statements on Crohn's disease. Part 1: Definition, diagnosis, and epidemiology (Asia Pacific Crohn's Disease Consensus- Part 1). Gastroenterol Hepatol. 2015;31:45-55.
29. Manninen P, Karvonen AL, Huhtala H, Rasmussen M, Collin P. The epidemiology of inflammatory bowel diseases in Finland. Scand J Gastroenterol. 2010;45:1063-7.

30. Tozun N, Atug O, Imeryuz N, Hamzaoglu HO, Tiftikci A, Parlak E, et al Clinical characteristics of inflammatory bowel disease in Turkey: a multicenter epidemiologic survey. J Clin Gastroenterol. 2009;43:51-7.

31. Lakatos L, Kiss LS, David G, Pandur T, Erdelyi Z, Mester G, et al. Incidence, disease phenotype at diagnosis, and early disease course in inflammatory bowe diseases in Western Hungary, 2002-2006. Inflamm Bowel Dis. 2011;17:2558-65.

32. Ramos GP, Papadakis KA. Mechanisms of Disease: Inflammatory Bowel Diseases. Mayo Clin Proc. 2019;94:155-65.

33. Silva BC, Lyra AC, Mendes CM, Ribeiro CP, Lisboa SR, de Souza MT, et al. The Demographic and Clinical Characteristics of Ulcerative Colitis in a Northeast Brazilian Population. Biomed Res Int. 2015;2015:359130.

34. Kaplan GG. The global burden of IBD: from 2015 to 2025. Nat Rev Gastroenterol Hepatol. 2015;12:720-7.

35. Lakatos L, Pandur T, David G, Balogh Z, Kuronya P, Tollas A, et al. Association of extraintestinal manifestations of inflammatory bowel disease in a province of western Hungary with disease phenotype: results of a 25-year follow-up study. World J Gastroenterol. 2003;9:2300-7.

36. D'Incà R, Podswiadek M, Ferronato A, Punzi L, Salvagnini M, Sturniolo GC. Articular manifestations in inflammatory bowel disease patients: a prospective study. Dig Liver Dis. 2009;41:565-9.

37. Farhi D, Cosnes J, Zizi N, Chosidow O, Seksik P, Beaugerie L, et al. Significance of erythema nodosum and pyoderma gangrenosum in inflammatory bowel diseases: a cohort study of 2402 patients. Medicine (Baltimore). 2008;87:281-93.

38. Dignass A, Eliakim R, Magro F, Maaser C, Chowers Y, Geboes K, et al. Second European evidence-based consensus on the diagnosis and management of ulcerative colitis part 1: definitions and diagnosis. J Crohns Colitis. 2012;6:965-90.

39. Cosnes J, Cattan S, Blain A, Beaugerie L, Carbonnel F, Parc R, et al. Longterm evolution of disease behavior of Crohn's disease. Inflamm Bowel Dis. 2002;8:244-50.

40. Jess T, Riis L, Vind I, Winther KV, Borg S, Binder V, et al. Changes in clinica characteristics, course, and prognosis of inflammatory bowel disease during the last 5 decades: a population-based study from Copenhagen, Denmark. Inflamm Bowel Dis. 2007;13:481-9.

41. Burisch J, Pedersen N, Cukovic-Cavka S, Turk N, Kaimakliotis I, Duricova D, et al. Environmental factors in a population-based inception cohort of inflammatory bowel disease patients in Europe-an ECCO-EpiCom study. J Crohn Colitis. 2014;8:607-16

42. Hanauer SB, Sandborn WJ, Lichtenstein GR. Evolving Considerations for Thiopurine Therapy for Inflammatory Bowel Diseases-A Clinical Practice Update: Commentary. Gastroenterology. 2019;156:36-42.

43. Bernstein CN, Loftus EV, Ng SC, Lakatos PL, Moum B. Hospitalisations and surgery in Crohn's disease. Gut. 2012;61:622-9.

44. Bechara CS, Lacerda Filho A, Ferrari MLA, Andrade DAR, Luz MMP, Silva RG. Caracterização de pacientes operados por doença de Crohn pela classificação de Montreal e identificação de fatores preditores de sua recorrência cirúrgica. Rev Col Bras Cir. 2015:42:97-105.

45. Targownik LE, Singh H, Nugent Z, Bernstein CN. The epidemiology of colectomy in ulcerative colitis: results from a population-based cohort. Am J Gastroenterol. 2012; 107:1228-35 